\title{
Uterine Cavity Abnormalities in Patients with Endometriosis in Alexandria: A Diagnostic Test Accuracy Study
}

\author{
Eman Aly Abd El Fattah \\ Department of Obstetrics and Gynecology, Faculty of Medicine, Shatby Maternity Hospital, Alexandria University, Alexandria, Egypt \\ Correspondence should be addressed to Eman Aly Abd El Fattah; eman0eman0eman7@gmail.com
}

Received 18 February 2017; Accepted 30 April 2017; Published 30 May 2017

Academic Editor: Enrique Hernandez

Copyright (C) 2017 Eman Aly Abd El Fattah. This is an open access article distributed under the Creative Commons Attribution License, which permits unrestricted use, distribution, and reproduction in any medium, provided the original work is properly cited.

\begin{abstract}
Endometriosis is strongly associated with infertility. Endometrial polyps are prevalent in infertile women and they have similar pathological characteristics to endometriosis, suggesting a possible association. Uterine malformations as uterine septum and hypoplastic uterus are also linked to endometriosis. Hysterosalpingogram and transvaginal ultrasonography are used to diagnose endometrial lesions. Hysteroscopy can detect small lesions that might be missed. Recently, 4D ultrasonography is being used, but which is superior has not been established yet. We aim to compare $4 \mathrm{D}$ ultrasonography to office hysteroscopy in evaluating uterine cavity in cases with endometriosis; also we aim at correlating these findings with the stage of endometriosis. 50 cases of endometriosis diagnosed by laparoscopy were randomly selected from El Shatby fertility clinic, Alexandria University, Egypt, with exclusion of cases with any previous intrauterine surgery or any hormonal treatment. Transvaginal 4D ultrasonography and office hysteroscopy were done. 4D ultrasonography agreed with office hysteroscopy in diagnosing abnormal uterine findings in 14 cases and four additional cases were diagnosed by hysteroscopy alone. Conclusion. Endometrial polyps, septate uterus, and hypoplastic uterus are more prevalent among infertile women who happen to have endometriosis. 4D ultrasonography and office hysteroscopy are equally successful in assessing the uterine cavity.
\end{abstract}

\section{Introduction}

It is estimated that endometriosis occurs in $10 \%$ of women during the reproductive years [1]. It has been classified into superficial, deep, and ovarian types. The superficial type may be presented as classical implants and vesicular, popular, nodular, haemorrhagic, healed, and apparently normal peritoneum [2]. It commonly presents between 25 and 29 years of age [1]. It is strongly associated with infertility, which is attributed to distorted adnexal anatomy [3], interference with oocyte development or early embryogenesis [4], or reduced endometrial receptivity [5]. Several studies have suggested impairment of implantation which may be due to intrinsic deficiencies within the uterus [6] and structural or ultrastructural defects [7]. Endometrial polyps are common gynecological disorder whose prevalence is increased in infertile women [8]. The exact pathogenesis of these polyps is not yet known, but the similar pathological characteristics to endometriosis suggest a possible association [9]. Anatomical uterine malformations are also linked to endometriosis [10]. Uterine septum, the most common Müllerian duct anomaly, results in colicky uterine peristalsis and increased menstrual regurgitation through the fallopian tubes [11]. Hypoplastic uterus, a rare anomaly, may be also associated [12]. Both hysterosalpingogram and transvaginal ultrasonography are used to diagnose endometrial lesions but sometimes they are not enough [13]. Hysteroscopy, the gold standard for evaluation of uterine causes of infertility, can detect small lesions that might not otherwise be detected by other methods [14]. In the recent years, office hysteroscopy has been preferred to operative hysteroscopy in routine evaluation of the endometrial cavity [15]. Recently, 4D ultrasonography is being used for the same purpose but which is superior has not been established yet. In this study, we aim to compare between $4 \mathrm{D}$ ultrasonography and office hysteroscopy in evaluating uterine cavity in cases with endometriosis. 


\section{Patients and Methods}

A prospective observational study was conducted on 50 cases of endometriosis which is the number needed to estimate the prevalence of uterine cavity abnormalities which is equal to $69 \%$ [16] with $12 \%$ precision (due to high variability at the estimated rates) using an alpha error of 5\% [17]. The sample was selected randomly using the simple random technique.

All patients were recruited from El Shatby fertility clinic, Alexandria University. Endometriosis was diagnosed by laparoscopy (discrete endometriotic lesions, endometriomas, or adhesions) [18] or transvaginal ultrasonography for endometriomas (cystic lesion with low level internal echoes, occasional thick septations, thickened walls, and echogenic wall foci) [19]. Patients with history of any previous intrauterine cavity or those receiving any hormonal treatment for the previous six months were excluded.

2.1. Methods. Informed consent was signed by all participants; complete history was taken (age, gravidity, parity, menstrual history, and previous surgery; complete examination (general, abdominal, and vaginal) was done. Transvaginal 4D ultrasonography was done in the dorsal lithotomy position. Uterus was assessed in the transverse and sagittal planes, adnexa were scanned for cysts or endometriotic nodules, and tubes were scanned for hydrosalpinx.

Office hysteroscopy was done immediately after menstruation using normal saline as distention media and $5 \mathrm{~mm}$ continuous flow sheath with an operative channel for the use of scissors, grasping forceps, or biopsy forceps when necessary. Light was provided by normal cold light source. During the procedure, the patient was placed in the dorsal lithotomy position, vulva and vagina were cleaned with antiseptic solution, the technique avoided the use of a speculum or a tenaculum, the vagina as a cavity was distended using the hysteroscope introduced into its lower part, and the anatomy was followed up till the cervical canal onto the uterine cavity. The uterine cavity was inspected symmetrically and the tubal ostia were identified; then the hysteroscope was pulled backwards to obtain a panoramic view of the whole cavity, and cervical canal was inspected during withdrawal. Findings were recorded. Polyps, when seen, were biopsied with biopsy forceps introduced through the operative channel and the diagnosis was confirmed with histopathological examination.

2.1.1. Statistical Methodology. Data were collected and entered to the computer using SPSS (Statistical Package for Social Sciences) program for statistical analysis (ver. 21) [20]. Data were entered as numerical or categorical, as appropriate. When Kolmogorov-Smirnov test revealed no significance in the distribution of variables, parametric statistics were carried out, while in the not-normally distributed data the nonparametric statistics were carried out [21]:

(i) Data were described using minimum, maximum, mean, and standard deviation for the normally distributed data.

(ii) Interrater (interobserver) agreement was carried out using kappa and weighted kappa tests [20, 22].

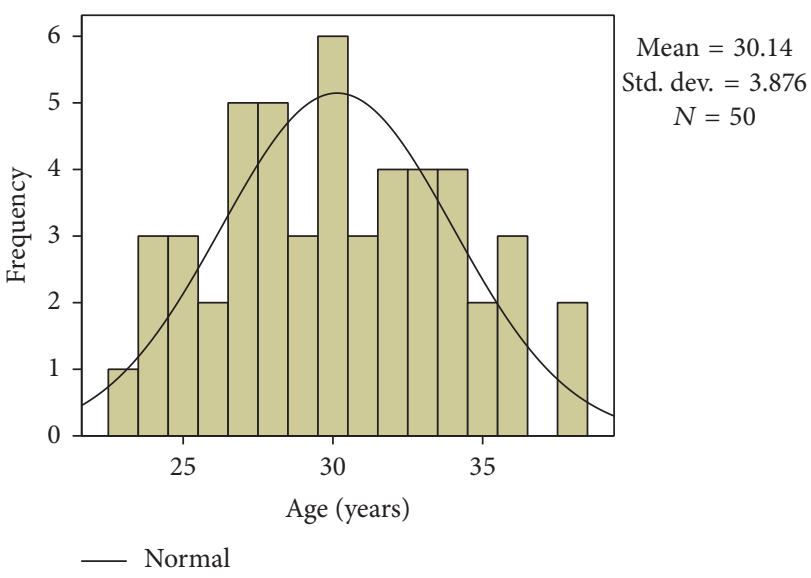

FIGURE 1: Histogram showing age distribution.

Proportions of specific agreement were calculated according to Spitzer and Fleiss [23].

An alpha level was set to $5 \%$ with a significance level of $95 \%$, and a beta error was accepted up to $20 \%$ with a power of study of $80 \%$.

2.1.2. Agreement Analysis. Magnitude guidelines have appeared in the literature. Perhaps the first were Landis and Koch [24] who characterized values $<0$ as indicating no agreement and $0-0.20$ as slight, $0.21-0.40$ as fair, $0.41-0.60$ as moderate, $0.61-0.80$ as substantial, and $0.81-1$ as almost perfect agreement. This set of guidelines is, however, by no means universally accepted; Landis and Koch supplied no evidence to support it, basing it instead on personal opinion. It has been noted that these guidelines may be more harmful than helpful [25]. Fleiss's [26] equally arbitrary guidelines characterize kappa over 0.75 as excellent, 0.40 to 0.75 as fair to good, and below 0.40 as poor.

\section{Results}

The study was conducted upon fifty cases of endometriosis; their age ranged from 23 to 38 years of age with a mean of $30 \pm 3.876$ years (Figure 1). 42 cases complained of primary infertility, while 8 cases complained of secondary infertility. By laparoscopy, we had 8 cases in stage I, 17 cases in stage II, 4 cases in stage III, 20 cases in stage IV, and one missing case. Endometriomas were found in 38 cases only (Table 1).

By 4D ultrasonography, we had abnormal uterine findings in 14 cases and this was confirmed by office hysteroscopy. On the contrary, 36 cases were completely normal by $4 \mathrm{D}$ ultrasonography but, by office hysteroscopy, 3 cases had abnormal findings which are statistically significant (Table 2). $4 \mathrm{D}$ ultrasonography had sensitivity of $82.35 \%$ and specificity of $100 \%$ for diagnosing abnormal uterine findings with a positive predictive value of $100 \%$ and a negative predictive value of $91.67 \%$ and an overall test accuracy of $94 \%$.

Abnormal findings were in the form of polyps, septate uterus, and hypoplastic uterus. Endometrial polyps were found in 8 cases by $4 \mathrm{D}$ ultrasonography which was confirmed by hysteroscopy (positive agreement), and $4 \mathrm{D}$ 
TABLE 1: Frequency of infertility and stage of endometriosis and endometrioma in the studied patients.

\begin{tabular}{lcc}
\hline & $n$ & $\%$ \\
\hline $\begin{array}{l}\text { Infertility } \\
\text { (i) Primary }\end{array}$ & 42 & 84.0 \\
$\quad$ (ii) Secondary & 8 & 16.0 \\
Stage & & \\
$\quad$ (i) I & 8 & 16.3 \\
(ii) II & 17 & 34.7 \\
(iii) III & 4 & 8.2 \\
(iv) IV & 20 & 40.8 \\
Endometriosis & & \\
(i) Negative & 38 & 76.0 \\
(ii) Positive & 12 & 24.0 \\
\hline
\end{tabular}

TABle 2: Overall diagnosis (success of hysteroscopy to diagnose polyps as well as uterine anomalies).

\begin{tabular}{lccc}
\hline & \multicolumn{2}{c}{ Hysteroscopy } & \multirow{2}{*}{ Total } \\
& Negative & Positive & \\
\hline 4D U/S & $33(66.0 \%)$ & $3(6.0 \%)$ & $36(72.0 \%)$ \\
Negative & $0(0.0 \%)$ & $14(28.0 \%)$ & $14(28.0 \%)$ \\
Positive & $33(66.0 \%)$ & $17(34.0 \%)$ & $50(100.0 \%)$ \\
\hline Total & 0.860 & \\
\hline Kappa & 0.077 & \\
Standard error & $0.000^{*}$ & \\
p value & 0.860 & \\
\hline Weighted kappa & 0.077 & \\
Standard error & $0.709-1.000$ & \\
95\% CI & & \\
\hline
\end{tabular}

Proportions of specific agreement: (i) negative agreement $=2 * 33 /(2 * 33+$ $3+0)=95.65 \%$; (ii) positive agreement $=2 * 14 /(2 * 14+3+0)=90.32 \%$. $*$ indicates significance.

ultrasonography diagnosed 42 cases as being normal which also agreed with hysteroscopy; only 2 cases were positive for the presence of polyps by hysteroscopy and they were diagnosed as free by $4 \mathrm{D}$ ultrasonography (Table 3). 4D ultrasonography had sensitivity of $80.00 \%$ and specificity of 95.24\% for diagnosing endometrial polyps with a positive predictive value of $80 \%$ and a negative predictive value of $95.24 \%$ and an overall test accuracy of $92.31 \%$.

Septate uterus was found in only 4 cases by $4 \mathrm{D}$ ultrasonography against 46 free cases. This was proven by hysteroscopy (positive agreement) in addition to one case which was diagnosed as free by $4 \mathrm{D}$ ultrasonography, but a septum was found on hysteroscopy (Table 4). 4D ultrasonography had sensitivity of $80.00 \%$ and specificity of $100.00 \%$ for diagnosing septate uterus with a positive predictive value of $100.00 \%$ and a negative predictive value of $97.83 \%$ and an overall test accuracy of $98.00 \%$.

Hypoplastic uterus was found in only 2 cases by $4 \mathrm{D}$ ultrasonography against 48 free cases which was the same result obtained by hysteroscopy (positive agreement) (Table 5). 4D ultrasonography had sensitivity of $100.00 \%$ and specificity of
TABLE 3: Endometrial polyps.

\begin{tabular}{lccc}
\hline & \multicolumn{2}{c}{ Hysteroscopy } & \multirow{2}{*}{ Total } \\
& Negative & Positive & \\
\hline 4D U/S & & & \\
Negative & $40(80.0 \%)$ & $2(4.0 \%)$ & $42(84.0 \%)$ \\
Positive & $0(0.0 \%)$ & $8(16.0 \%)$ & $8(16.0 \%)$ \\
\hline Total & $40(80.0 \%)$ & $10(20.0 \%)$ & $50(100.0 \%)$ \\
\hline Kappa & 0.865 \\
Standard error & 0.093 & \\
p value & $0.000^{*}$ & \\
Weighted kappa & 0.865 & \\
Standard error & 0.093 \\
95\% CI & $0.683-1.000$ & \\
\hline
\end{tabular}

Proportions of specific agreement: (i) negative agreement $=2 * 40 /(2 * 40+$ $2+0)=97.56 \%$; (ii) positive agreement $=2 * 8 /(2 * 8+2+0)=88.89 \%$. * indicates significance.

TABLE 4: Uterine septum.

\begin{tabular}{lccc}
\hline & \multicolumn{2}{c}{ Hysteroscopy } & \multirow{2}{*}{ Total } \\
& Negative & Positive & \\
\hline 4D U/S & & & \\
Negative & $45(90.0 \%)$ & $1(2.0 \%)$ & $46(92.0 \%)$ \\
Positive & $0(0.0 \%)$ & $4(8.0 \%)$ & $4(8.0 \%)$ \\
\hline Total & $45(90.0 \%)$ & $5(10.0 \%)$ & $50(100.0 \%)$ \\
\hline Kappa & 0.878 & \\
Standard error & 0.120 & \\
p value & $0.000^{*}$ & \\
Weighted kappa & \multicolumn{2}{c}{0.878} \\
Standard error & 0.120 & \\
95\% CI & $0.643-1.000$ & \\
\hline
\end{tabular}

Proportions of specific agreement: (i) negative agreement $=2 * 45 /(2 * 45+$ $1+0)=98.90 \%$; (ii) positive agreement $=2 * 4 /(2 * 4+1+0)=88.89 \%$ * indicates significance.

$100.00 \%$ for diagnosing hypoplastic uterus with a positive predictive value of $100.00 \%$ and a negative predictive value of $100.00 \%$ and an overall test accuracy of $100.00 \%$.

\section{Discussion}

Endometriosis is a common gynecological disorder; its association with infertility is complex and controversial. Virtually, every aspect of reproduction in women with endometriosis has been investigated. Although advanced stages may manifest easily recognizable infertility factors, such as tubal distortion or obstruction, the mechanisms underlying reproductive dysfunction in women with minimal or mild disease are more subtle [27]. Many studies were conducted on endometriosis patients and many hypotheses exist to explain the relation between it and infertility but still the precise mechanism remains unclear. Our study aimed at evaluating the uterine cavity in those patients by $4 \mathrm{D}$ ultrasonography and by hysteroscopy and we also aimed at comparing these two methods to each other. $4 \mathrm{D}$ ultrasonography has the advantage of exact volume measurement of endometrial polyps which 
TABle 5: Hypoplastic uterus.

\begin{tabular}{|c|c|c|c|}
\hline & \multicolumn{2}{|c|}{ Hysteroscopy } & \multirow{2}{*}{ Total } \\
\hline & Negative & Positive & \\
\hline \multicolumn{4}{|l|}{$4 \mathrm{D} \mathrm{U} / \mathrm{S}$} \\
\hline Negative & $48(96.0 \%)$ & $0(0.0 \%)$ & $48(96.0 \%)$ \\
\hline Positive & $0(0.0 \%)$ & $2(4.0 \%)$ & $2(4.0 \%)$ \\
\hline Total & $48(96.0 \%)$ & $2(4.0 \%)$ & $50(100.0 \%)$ \\
\hline Kappa & \multicolumn{2}{|c|}{1.000} & \\
\hline Standard error & \multicolumn{2}{|c|}{0.000} & \\
\hline$p$ value & \multicolumn{2}{|c|}{$0.000^{*}$} & \\
\hline Weighted kappa & \multicolumn{2}{|c|}{1.000} & \\
\hline Standard error & \multicolumn{2}{|c|}{0.000} & \\
\hline $95 \% \mathrm{CI}$ & \multicolumn{2}{|c|}{$1.000-1.000$} & \\
\hline
\end{tabular}

Proportions of specific agreement: (i) negative agreement $=2 * 48 /(2 * 48+$ $0+0)=100.0 \%$; (ii) positive agreement $=2 * 2 /(2 * 2+0+0)=100.0 \%$. $*$ indicates significance.

cannot be achieved by 2D ultrasonography. We succeeded in proving that $4 \mathrm{D}$ ultrasonography could be a good diagnostic tool for diagnosing abnormal uterine findings with a positive predictive value of $100 \%$ and an overall test accuracy of $94 \%$. Hypoplastic uterus was the main abnormal uterine finding that could be detected with $4 \mathrm{D}$ ultrasonography with an overall test accuracy of $100 \%$ but unfortunately this was not the case for endometrial polyps where the overall test accuracy was $92.31 \%$

After searching the literature, we found two studies reporting high prevalence of endometrial polyps in endometriosis patients $[16,28]$ and one study reporting uterine anomalies [29]. These studies aimed at just finding a relation or an association between abnormal uterine cavity findings and endometriosis and they did not recommend a particular diagnostic tool but, on the other hand, they used 2D ultrasonography, hysterosalpingography, and hysteroscopy without showing which of these methods was superior to the others.

Functional endometrial polyps which are confined to hormonally responsive layer of the uterus are estrogendependent. The exact pathogenesis of these benign lesions is not well known, but hormonal dysfunction is the most accepted theory [30]. In a study done by Hinckley and Milki upon 1000 infertile patients in 2004, prevalence of endometrial polyps was $35 \%$ only [29]. A larger study conducted upon 2500 infertile patients in 2010 reported prevalence of $7.86 \%$ [8]. In this study, researchers recommended hysteroscopy in comparison to ultrasonography for diagnosing endometrial polyps but they used the $2 \mathrm{D}$ ultrasonography and not the $4 \mathrm{D}$ one. The similar characteristics of endometriosis and endometrial polyps suggest a possible association between them. In 2003, Kim et al. studied one hundred eighty-three infertile women: 92 of them had endometriosis and 91 were control. They found polyps in 43 women in the endometriotic group (46.7\%) against 15 women in the control group (16.5\%) [28].

In 2011, Shen et al. studied 431 cases: 158 cases with endometriosis and 273 cases without endometriosis.
Endometrial polyps were found in 108/158 cases (68.35\%) with endometriosis and in 56/273 cases of the control group (20.51\%) [16]. These results agree with our results as regards the high prevalence of polyps in endometriosis patients. The difference in the prevalence could be due to the number of characteristics and the different population, as the studies were held in China with the consideration of the high prevalence of endometrial polyps in this population.

Our study also evaluated the uterine cavity for uterine anomalies and we reported five cases of septate uterus (10\%) and two cases of hypoplastic uterus (4\%). The incidence of congenital uterine anomalies in the general population is $0.1-3 \%[31]$.

Hinckley and Milki studied 1385 infertile cases, of which 7 cases $(0.5 \%)$ had uterine septum [29]. Matalliotakis et al. studied 425 cases with endometriosis and 200 cases without endometriosis in 2010. They found 13 cases from 425 having a uterine septum, representing 3\%. The control group had only one case, representing $0.5 \%$ of the studied group [32]. This agrees with our results, but they did not differentiate between the different diagnostic modalities as we did. Comparing $4 \mathrm{D}$ ultrasonography to office hysteroscopy, a positive agreement was found, where only one case of septate uterus was missed by $4 \mathrm{D}$ and reported by office hysteroscopy; otherwise both reported the same findings as regards polyps and hypoplastic uterus. This proves that $4 \mathrm{D}$ ultrasonography with its advantage as an easy noninvasive technique could be used instead of office hysteroscopy.

\section{Conclusion}

From the present study, we concluded that endometrial polyps, septate uterus, and hypoplastic uterus are more prevalent among infertile women who happen to have endometriosis. Both $4 \mathrm{D}$ ultrasonography and office hysteroscopy are equally successful in assessing the uterine cavity but ultrasonography has the advantage of being an easy noninvasive maneuver.

\section{Conflicts of Interest}

The author declares that there are no conflicts of interest.

\section{References}

[1] S. Simoens, L. Hummelshoj, and T. D’Hooghe, "Endometriosis: cost estimates and methodological perspective," Human Reproduction Update, vol. 13, no. 4, pp. 395-404, 2007.

[2] K. J. Boyle and S. Torrealday, "Benign gynecologic conditions," Surgical Clinics of North America, vol. 88, no. 2, pp. 245-264, 2008.

[3] C. Allaire, "Endometriosis and infertility: a review," The Journal of Reproductive Medicine, vol. 51, no. 3, pp. 164-168, 2006.

[4] J. Navarro, N. Garrido, J. Remohí, and A. Pellicer, "How does endometriosis affect infertility?" Obstetrics and Gynecology Clinics of North America, vol. 30, no. 1, pp. 181-192, 2003.

[5] J. J. Kim, H. S. Taylor, and Z. Lu, "Altered expression of HOXA 10 in endometriosis: potential role in decidualisation," Molecular Human Reproduction Journal, vol. 13, pp. 323-332, 2007. 
[6] N. Garrido, J. Navarro, J. García-Velasco, J. Remohí, A. Pellicer, and C. Simón, "The endometrium versus embryonic quality in endometriosis-related infertility," Human Reproduction Update, vol. 8, no. 1, pp. 95-103, 2002.

[7] L. Fedele, M. Marchini, S. Bianchi, M. Dorta, L. Arcaini, and P. E. Fontana, "Structural and ultrastructural defects in preovulatory endometrium of normo-ovulating infertile women with minimal or mild endometriosis," Fertility and Sterility, vol. 53, no. 6, pp. 989-993, 1990.

[8] R. Karayalcin, S. Ozcan, O. Moraloglu, S. Ozyer, L. Mollamahmutoglu, and S. Batioglu, "Results of 2500 office-based diagnostic hysteroscopies before IVF," Reproductive BioMedicine Online, vol. 20, no. 5, pp. 689-693, 2010.

[9] J. H. McBean, M. Gibson, and J. R. Brumsted, "The association of intrauterine filling defects on hysterosalpingogram with endometriosis," Fertility and Sterility, vol. 66, no. 4, pp. 522-526, 1996.

[10] J. S. Sanfilippo, N. G. Wakim, K. N. Schikler, and M. A. Yussman, "Endometriosis in association with uterine anomaly," American Journal of Obstetrics \& Gynecology, vol. 154, no. 1, pp. 39-43, 1986.

[11] V. Sparac, S. Kupesic, M. Ilijas, T. Zodan, and A. Kurjak, "Histologic architecture and vascularization of hysteroscopically excised intrauterine septa," Journal of the American Association of Gynecologic Laparoscopists, vol. 8, no. 1, pp. 111-116, 2001.

[12] A. S. D. Wold, N. Pham, and A. Arici, "Anatomic factors in recurrent pregnancy loss," Seminars in Reproductive Medicine, vol. 24, no. 1, pp. 25-32, 2006.

[13] S. R. Soares, M. M. B. B. Dos Reis, and A. F. Camargos, "Diagnostic accuracy of sonohysterography, transvaginal sonography, and hysterosalpingography in patients with uterine cavity diseases," Fertility and Sterility, vol. 73, no. 2, pp. 406-411, 2000.

[14] J. S. L. Cunha-Filho, C. A. B. De Souza, C. C. Salazar, A. C. Facin, F. M. Freitas, and E. P. Passos, "Accuracy of hysterosalpingography and hysteroscopy for diagnosis of intrauterine lesions in infertile patients in an assisted fertilization programme," Gynaecological Endoscopy, vol. 10, no. 1, pp. 45-48, 2001.

[15] S. Bettocchi, O. Ceci, R. Di Venere et al., "Advanced operative office hysteroscopy without anaesthesia: Analysis of 501 cases treated with a 5 Fr. bipolar electrode," Human Reproduction, vol. 17, no. 9, pp. 2435-2438, 2002.

[16] L. Shen, Q. Wang, W. Huang et al., "High prevalence of endometrial polyps in endometriosis-associated infertility," Fertility and Sterility, vol. 95, no. 8, pp. 2722.el-2724.el, 2011.

[17] W. Daniel, Biostatistics. A foundation for Analysis in The Health Science, John Wiley and sons, New York, NY, USA, 6th edition, 1995.

[18] J. Moore, S. Copley, J. Morris, D. Lindsell, S. Golding, and S. Kennedy, "A systematic review of the accuracy of ultrasound in the diagnosis of endometriosis," Ultrasound in Obstetrics and Gynecology, vol. 20, no. 6, pp. 630-634, 2002.

[19] S. Kennedy, "Should a diagnosis of endometriosis be sought in all symptomatic women?" Fertility and Sterility, vol. 86, no. 5, pp. 1312-1313, 2006.

[20] IBM Corp, IBM SPSS Statistics for Windows, Version 21.0., IBM Corp., Armonk, NY, USA, 2012.

[21] A. Field, Ed., Discovering Statistics Using SPSS, SAGE Publications Ltd, London, UK, 2nd edition, 2006.

[22] MedCalc Statistical Software version 14.8.1, MedCalc Software bvba, Ostend, Belgium, 2014, http://www.medcalc.org.
[23] R. L. Spitzer and J. L. Fleiss, "A re-analysis of the reliability of psychiatric diagnosis," The British Journal of Psychiatry, vol. 125, no. 587, pp. 341-347, 1974.

[24] J. R. Landis and G. G. Koch, "The measurement of observer agreement for categorical data," Biometrics, vol. 33, no. 1, pp. 159-174, 1977.

[25] K. Gwet, Handbook of Inter-Rater Reliability, 2nd edition, 2010.

[26] J. L. Fleiss, Statistical Methods for Rates and Proportions, John Wiley, New York, NY, USA, 2nd edition, 1981.

[27] M. Toya, H. Saito, N. Ohta, T. Saito, T. Kaneko, and M. Hiroi, "Moderate and severe endometriosis is associated with alterations in the cell cycle of granulosa cells in patients undergoing in vitro fertilization and embryo transfer," Fertility and Sterility, vol. 73, no. 2, pp. 344-350, 2000.

[28] M. R. Kim, Y. A. Kim, M. Y. Jo, K. J. Hwang, and H. S. Ryu, "High frequency of endometrial polyps in endometriosis," The Journal of the American Association of Gynecologic Laparoscopists, vol. 10, no. 1, pp. 46-48, 2003.

[29] M. D. Hinckley and A. A. Milki, "1000 office-based hysteroscopies prior to in vitro fertilization: feasibility and findings," Journal of the Society of Laparoendoscopic Surgeons, vol. 8, no. 2, pp. 103-107, 2004.

[30] F. M. Carvalho, F. N. Aguiar, R. Tomioka, R. M. De Oliveira, N. Frantz, and J. Ueno, "Functional endometrial polyps in infertile asymptomatic patients: a possible evolution of vascular changes secondary to endometritis," European Journal of Obstetrics Gynecology and Reproductive Biology, vol. 170, no. 1, pp. 152-156, 2013.

[31] P. Acien and M. Acien, "Evidence-based management of recurrent miscarriage," International Congress Series, vol. 1, no. 266, pp. 335-342, 2004.

[32] I. M. Matalliotakis, A. G. Goumenou, M. Matalliotakis, and A. Arici, "Uterine anomalies in women with endometriosis," Journal of Endometriosis, vol. 2, no. 4, pp. 213-217, 2010. 


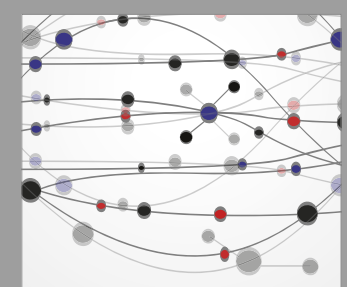

The Scientific World Journal
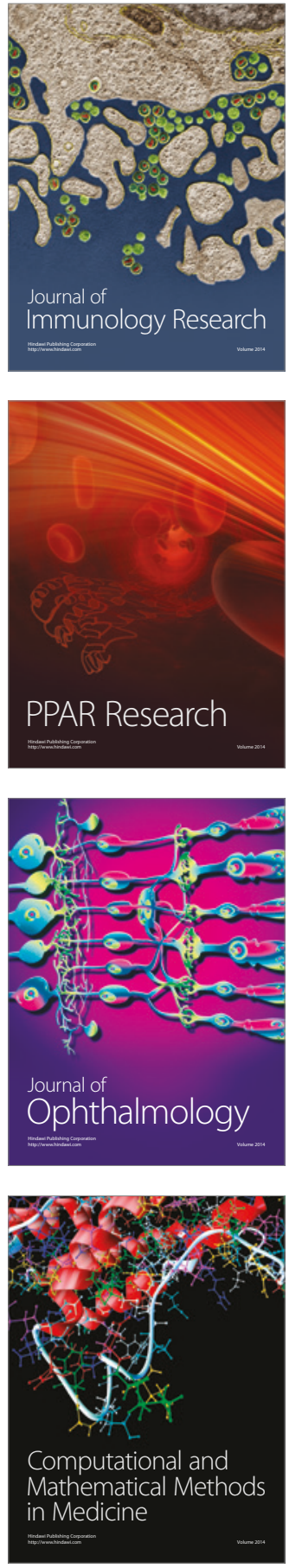

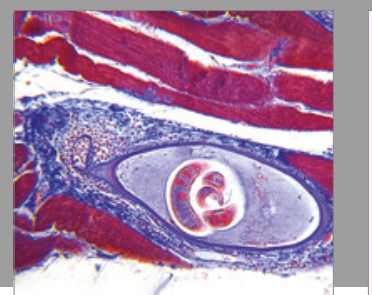

Gastroenterology Research and Practice
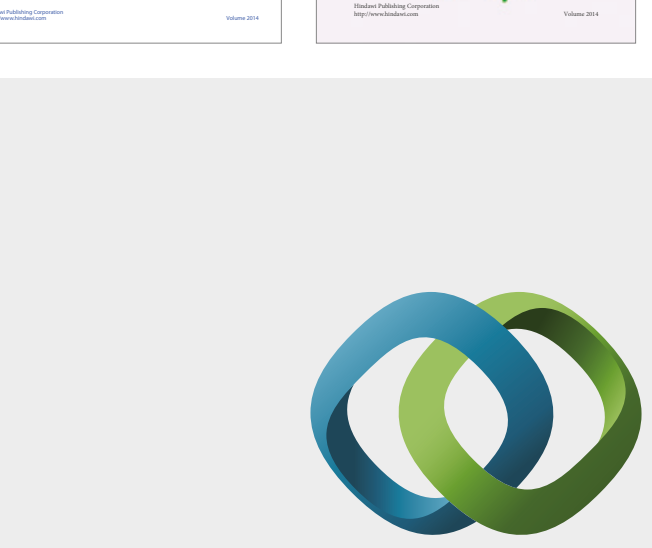

\section{Hindawi}

Submit your manuscripts at

https://www.hindawi.com
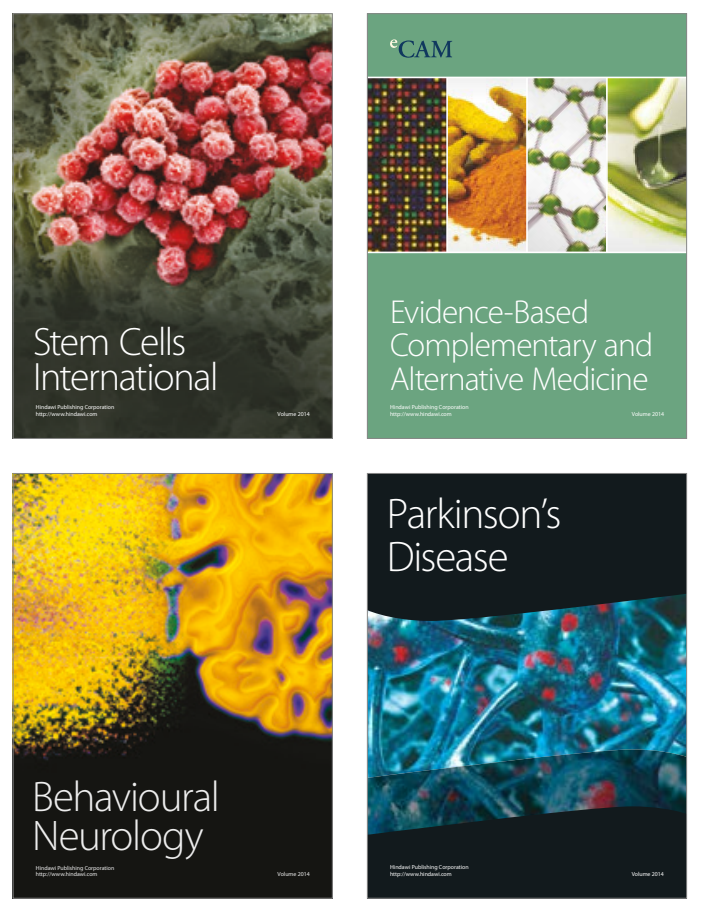
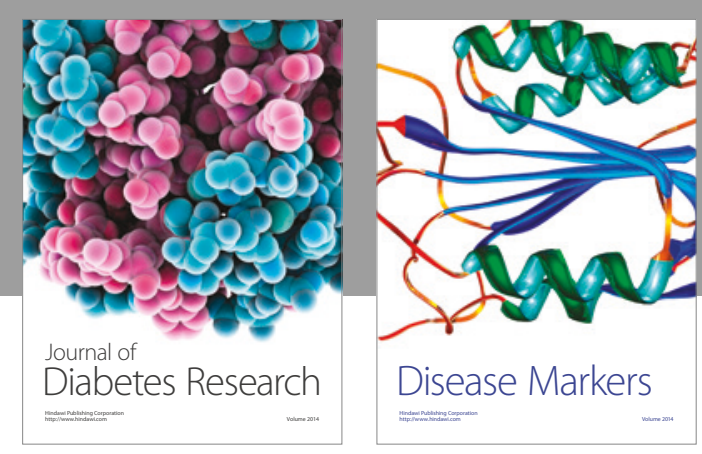

Disease Markers
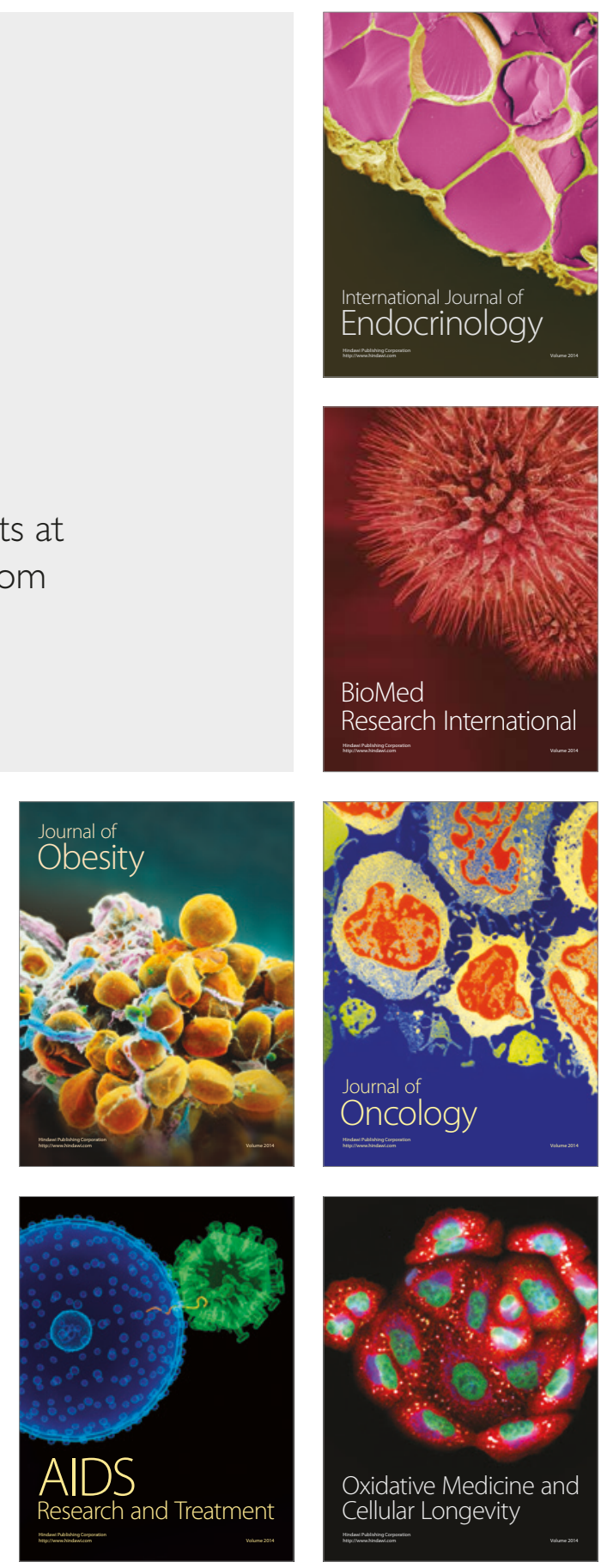